
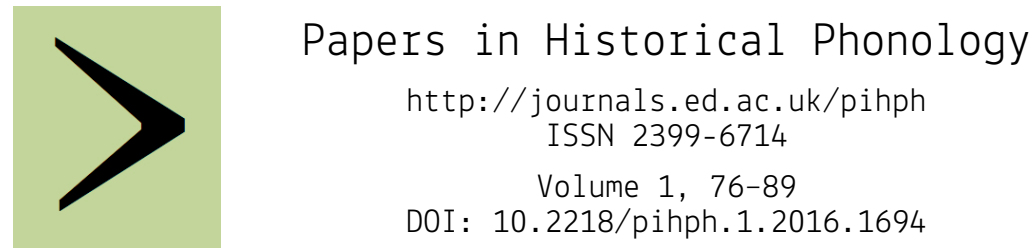

DOI: $10.2218 /$ pihph.1.2016.1694

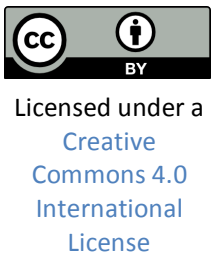

\title{
Tone loss in Sranan Creole: re-thinking contact driven change
}

\author{
EMILY BARTH \\ Cornell University
}

\begin{abstract}
Among the Surinamese creoles, Sranan is a stress-accent language whereas both Ndyuka and Saramaccan exhibit phonological tone in addition to stress. Previous attempts to explain this historical divergence understand tone loss in Sranan to be directly associated with its innovation of complex onsets modeled after Dutch. Appealing to the argument of Aceto (1996) for the presence of CR- onsets in early Surinamese Creole, I contend that it was the opposite innovation in the maroon creoles-removal of liquid clusters via epenthesis and consequent intervocalic liquid deletion, producing heavy syllables-that contributed to the survival of distinctive phonological tone.
\end{abstract}

\section{Introduction}

\subsection{Historical background}

Sranan, Ndyuka, and Saramaccan constitute a closely-related creole language family with origins in the multi-lingual setting of $17^{\text {th }}$ and early $18^{\text {th }}$ century Suriname. This is often said to be among the 'most conservative' of creole families due to its early isolation from English, the primary lexifier language, mere decades after its inception. All three creole lexicons incorporate words from both accentual European languages-mainly English, with additional borrowings from Portuguese and Dutch - and a substratum of African tonal languages.

Though Sranan was isolated very quickly from its primary superstrate, as a plantation creole it nevertheless remained in contact with other European languages throughout its history. Saramaccan and Ndyuka are both maroon offshoots of early Surinamese Creole, meaning that they were originally spoken and passed down by escaped plantation slaves who established independent communities in the bush. 
The Saramaccan maroons escaped between 1690 and 1710 from inland plantations whose creole dialect had already diverged from the common proto-creole under heavy Portuguese influence. Ndyuka was a later, direct offshoot from the Sranan-speaking coastal plantations, and as such generally diverges from Sranan far less than Saramaccan in terms of vocabulary and syntax. Yet both modern maroon creoles share some features that are often described as more 'conservative' than modern Sranan, which is attributed to their very early isolation not only from English but from all European superstrate contact. Perhaps the most conspicuous of these features, and the focus of the present study, is phonological tone. ${ }^{1}$

\subsection{Prosodic systems}

Modern Sranan has a purely stress-based prosodic system, and lacks phonological tone entirely. The placement of stress accent corresponds to the location of stress in European donor words, while historically unstressed syllables remain unstressed in creole forms.

Ndyuka and Saramaccan on the other hand both have phonological tone in addition to stress. In both languages, all tone bearing units are assigned either high or low tone. The placement of underlying high tone coincides with stress placement in the source language, and similarly, historically unstressed or epenthetic vowels receive low tone assignments. For example forms, see table 1, where modern Sranan and Saramaccan words are presented alongside historical forms from the mid-18 ${ }^{\text {th }}$ century.

\begin{tabular}{llllll} 
Etymon & Sranan & Sr. 1783 & Ndyuka & Saramaccan & Sm. 1778 \\
\hline foot & 'futu & futu & fútu & fútu & fútu \\
\hline snake & 'sneki & snekki & sinéki & sindéki & sneki \\
\hline today & ti'de & tideh & tidé & tidé & tidé \\
\hline Belly & 'bere & belle & bée & bëë & belle \\
\hline cassava & ka'saba & kassaba & kasába & kasába & kassaba \\
\hline
\end{tabular}

Table 1:Regular prosodic correspondences

The primary historical sources consulted in this paper are Schumann's 1778 wordlist for Saramaccan, comprising roughly 1,250

\footnotetext{
${ }^{1}$ For more information regarding the history of the Surinamese Creoles, see Carlin, Eithne B. \& Jacques Arends (eds.), Atlas of the Languages of Suriname (Leiden: KITLV Press, 2002) and Huttar, George, "The African lexical contribution to Ndyuka, Saramaccan, and other creoles," in Angela Bartens \& Philip Baker (eds.), Black through White: African words and calques which survived slavery in Creoles and transplanted European languages (London \& Colombo: Battlebridge, 2012), 215-229.
} 
lexical items with corresponding German translations, and his comparable 1783 wordlist for Sranan. Unfortunately no historical information is available for Ndyuka, which was not recorded prior to the $20^{\text {th }}$ century.

\subsection{Distinctive tone \& stress}

The picture is more complicated when it comes to stress placement in Ndyuka and Saramaccan. Huttar \& Huttar (1994: 565f.) observe that the placement of stress is fully predictable in modern Ndyuka: it generally falls on the penultimate syllable, but one major exception is that stress is drawn to heavy syllables regardless of their position in a word. Heavy syllables containing two vowel morae are a historical innovation in Ndyuka and Saramaccan, so this stress shift occurs as part of a chain of diachronic sound changes. For example in the Ndyuka word 'feemúsu 'bat' < *fele'músu < *fle'músu, an innovated long vowel in the antepenultimate syllable has drawn the stress away from the syllable containing the underlying high tone, but each TBU retains its original tone assignment. ${ }^{2}$

In Saramaccan, the rules for stress placement are much debated, but Rountree (1972) observes a similar tendency for what she calls 'long vowels' (rather than heavy syllables) to attract stress. Jeff Good (2009; 2012) makes several attempts to quantify rules for predicting stress from the position of underlying high tone, but though his various analyses differ he consistently notes that stress/tone mismatches may arise because the domain of stress is the syllable while the domain of tone is the individual mora.

The question naturally arises as to what factors and influences shaped the divergent development of the prosodic systems in these languages. Previous analyses have proposed that tone loss in Sranan is inextricably tied with a process of innovating onset clusters in emulation of Dutch syllable structure. But Aceto (1996) argues convincingly that clusters were not a recent innovation of Sranan, but an original feature of the early common Surinamese Creole. If so, then Sranan is the conservative one, at least with respect to syllable structure, if not tone.

\footnotetext{
2 Not all Ndyuka words behave uniformly in this regard. In a number of other lexical items, such as kondée 'country' and watáa 'water' (cf. Sranan kóndre and wátra, respectively), the placement of underlying high tone follows the shift in stress, moving to the first mora of the innovated long vowel. But Devonish (1989: 46) maintains that, since this stress-induced tone shift did not apply uniformly to all words with heavy syllables in the language, examples such as these do not constitute counter-evidence to the prevailing analysis that stress is independent from underlying $\mathrm{H}$-tone in Ndyuka.
} 
If this is the case, a new explanation is needed for Sranan tone loss. I suggest that the independent creation of heavy syllables in both Ndyuka and Saramaccan motivated these languages to preserve lexical tone, since the well-documented processes of vowel epenthesis and intervocalic liquid deletion ultimately resulted in the non-identical assignment of stress and tone. Since Sranan lacked these sequential epenthesis and deletion processes and never innovated heavy syllables, tone and stress remained in identical distribution. As such, the Sranan prosodic system was vulnerable to simplification under the long-standing influence of Dutch. Contact only comes into play, I argue, once there is such an independently motivated vulnerability in the Sranan prosodic system.

To demonstrate this, first I explain the phonotactic processes of creolization in greater detail, along with the synchronic reflexes in the modern creoles of various superstrate word-shape inputs. Then I discuss previous diachronic accounts of vowel epenthesis and liquid deletion, and how they affect re-syllabification and tone assignment. Finally, I introduce my new diachronic account of Sranan tone loss.

\section{Creolization Patterns}

\subsection{Re-syllabification}

Lexical items from European languages were incorporated into the early Surinamese Creole lexicon with regular modifications that simplified the syllable-structure inventory. This was primarily done by vowel epenthesis, and occasionally coda consonant deletion, as repair strategies to make loanwords conform to an optimal CV or CVN syllable template.

\begin{tabular}{llllll} 
Etymon & Sranan & Sr. 1783 & Ndyuka & Saramaccan & Sm. 1778 \\
\hline walk & 'waka & Wakka & wáka & wáka & wakka \\
\hline laugh & 'lafu & Laffo & láfu & láfu & laffo \\
\hline fight & 'feti & Feti & féti & féti & feti \\
\hline dead & 'dede & Dedde & déde & dwëdë & dedde \\
\hline nose & 'noso & Nussu & nósu & núsu & nusso \\
\hline one & wan & wan & wán & wán & wan \\
\hline sun & son & sonn & sán & sónu & sonn \\
\hline cunning & 'koni & konikoni, kunnikunni & kóni & köni & konni, kunni \\
\hline jump & 'djompo & djompo & djómbo & djómbo & djombo \\
\hline round & 'lontu & lundu, luntu, rundu & lóntu & lóntu & luntu, luluntu \\
\hline stink & 'tingi & tingi & tíngi & tíngi & tingi \\
\hline stand & tan & tann & tán & tán & tann \\
\hline lost & 'lasi & lasi & lási & lási & lási \\
\hline ripe & 'lepi & lepi, repi & lépi & lépi & - \\
\hline root & 'rutu & lutu & lútu & lútu & lutu \\
\hline live & 'libi & libi & líbi & líbí & libi \\
\hline
\end{tabular}

Table 2: Typical creolization patterns 


\subsection{Liquid consonants}

Descriptively, the liquid consonants /l/ and / $\mathrm{r}$ / have merged into /l/ in Ndyuka and Saramaccan, and to a certain extent in Sranan as well. Word-initially, liquids are retained without further alteration. But in other positions, the treatment of liquids is far more complex.

CR- onset clusters are to be found in all attested stages of Sranan, and they appear to have been allowed in early Saramaccan as well. But comparable sequences in modern Saramaccan and Ndyuka have evidently undergone two sound changes. First, a further process of vowel epenthesis, which may be schematized as $\emptyset>V_{\alpha} / C_{-} R V_{\alpha}$, produces CVRV sequences from inputs with original onset clusters. This is later followed by the deletion of liquids between vowels, ${ }^{3}$ which retain their original tone assignments.

Thus, an original input of the shape CRV appears as CVV in the maroon creoles. For example, English 'true' corresponds to Sranan tru but Ndyuka and Saramaccan tuú, with has a bimoraic vowel with LH rising tone contour derived through the process of CRV > CV'RV́ > 'CVV́. Original coda liquids also produce noteworthy forms. CVR inputs are 'repaired' by word-final vowel epenthesis, which is usuallyfollowed, again, by intervocalic liquid deletion. ${ }^{4}$ For example, English 'tar' corresponds to 'tara in Sranan. But the form in Ndyuka and Saramaccan is táa with a falling contour, derived through the process CVR > 'CV́RV > 'CV́V. ${ }^{5}$

Thus, descriptively, the Sranan sequences CVRV and CRV both correspond to CVV in the maroon creoles-but the maroon CVV sequences in question are distinguished by having falling and rising tone contours, respectively. Table 3 shows examples words with tone

\footnotetext{
${ }^{3}$ Certain non-liquid consonants also undergo intervocalic deletion. Original word-final voiced coronal obstruents merge with /l/ following final vowel epenthesis. Ndyuka and Saramaccan differ for the most part only in the retention vs. loss of the intervocalic consonant, respectively, while the vowel patterns are in agreement-if not always for quality, at least always for quantity and tone contours. There are also rare instances of voiceless obstruents deleted in the same environment, for example E. 'take' > Sranan 'teki, Ndyuka téke, Saramaccan téi (1778 teki) and E. 'if' > Sranan 'efi, Ndyuka éfu, Saramaccan éè (1778 effi).

${ }^{4}$ Rarely is the liquid retained following epenthesis, at least in borrowings dating to an early period, though it is perhaps less rare to encounter liquids retained in historically -VRV- input sequences, for example Saramaccan kulé 'run' < Port. correr.

${ }^{5}$ Incidentally Saramaccan also has a by-form 'tála where the liquid has been retained. Though intervocalic liquid deletion is extremely common, it is also an idiosyncratic rule with many exceptions. It is particularly common for liquids to be retained between non-identical vowels, as Ndyuka bóli 'boil’ demonstrates in Table 3.
} 
contours, including tonal minimal pairs, that have been innovated through this two-step process.

\begin{tabular}{llllll} 
Etymon & Sranan & Sr. 1783 & Ndyuka & Saramaccan & Sm. 1778 \\
\hline feel & firi & - & fíi & fíi & fill, fili \\
\hline free & fri & fri & fií & fií & fri \\
\hline dear & 'diri & diri (1855) & díi & díi & - \\
\hline D. drie & dri & dri & dii & dií & dri \\
\hline grow & gro & gro & góo & göö & gro \\
\hline true & tru & tru & tuú & tuú & tru \\
\hline boil & 'bori & boli, bori & bóli & bói & bôli \\
\hline creek & 'kriki & kríki (1855) & kiíki & kiíki & kriki, kieki \\
\hline play fool 'dare'6 & pre(j)'furu & pre(h)fulu & peefúu & peevú & prefure/u \\
\hline
\end{tabular}

Table 3: tone contours from liquid deletion

Sranan has allowed liquids both in intervocalic positions and in onset clusters throughout its recorded history, such that no heavy syllables have been created beyond a very few that derive from diphthongs in donor languages. ${ }^{7}$ In Ndyuka and Saramaccan the functional load of tone was expanded to distinguish tonal minimal pairs that arose as a direct consequence of epenthesis and liquid deletion. Though tone was very likely an active feature in the earliest stage of Sranan, its functional load was never expanded in a similar fashion because Sranan never underwent this sequence of re-syllabifying sound changes.

\section{Diachronic cluster treatments}

\subsection{Traditional accounts}

Establishing a chronology for these re-syllabification processes becomes important when it comes to theorizing what has motivated the preservation of tone in the maroon creoles and the loss of tone in Sranan. Traditional accounts of creole syllabification, such as Alleyne's 1980 comparative study of English-based Afro-American creoles, operate under the assumption that, during initial creolization, all

6 The outcomes of the English compound input 'play fool' demonstrate that unaccented syllables undergo the same processes of epenthesis and deletion as accented ones: Ndyuka peefúu and Saramaccan peevú share the initial syllable pee-, presumably from an intermediary form *pele-.

${ }^{7}$ Some diphthongs, shared by all three languages, derive from original diphthongs in the source language. They are nearly always in synchronically open syllables, and very often appear word-finally. But, the noteworthy contrast remains the fact that vowel length is not distinctive in Sranan, as it is in the maroon creoles. 
loanwords were incorporated into the proto-Atlantic creole lexicon with a universal CV syllable shape. Epenthesis during initial creolizationwould then feed two separate processes: syncope in Sranan would produce 'kriki, while liquid deletion in both Saramaccan and Ndyuka would produce kiíki.

Under this diachronic view, the stricter adherence to a $\mathrm{CV}(\mathrm{N})$ syllable template in the maroon creoles is thought to maintain a more conservative situation closer to the original state of early Surinamese Creole, even though liquid deletion in Saramaccan often obscures the relationship between modern words and their earlier forms in Schumann's 1778 wordlist and other early documents. Sranan's slightly larger inventory of syllable types and tolerance for liquid clusters is understood to be the later contact-induced development in emulation of European superstrates.

\subsection{An alternative timeline}

Aceto (1996) argues for a competing scenario-to which I ascribemaintaining that onset clusters were an original component of the early Surinamese proto-creole. This situation was preserved in Sranan but only later simplified in Ndyuka and Saramaccan via a regular sound change of epenthesis in CR- onset clusters, sometime after the compilation of Schumann's wordlist.

\begin{tabular}{lllll} 
Source & pre-1778 & epenthesis & liquid deletion & post-1778 \\
\hline P. 'fruta' & $>$ fruta & $>$ *furuta & $>$ fuuta & $>$ fuúta \\
\hline P. 'dormir' & $>$ drummi & $>$ *durumi & $>$ duumi & $>$ duúmi \\
\hline
\end{tabular}

Table 4: Aceto's timeline of changes

Aceto's argument is based first of all on the widespread and regular appearance of clusters in $18^{\text {th }}$ century Saramaccan documents. ${ }^{8}$ Also in

\footnotetext{
${ }^{8}$ In some cases, it could be argued that European compilers of the early wordlists were influenced by their awareness of the English donor words contributing to the creole lexicons. In particular much attention has been devoted to Saramaccan words that Schumann records with consonant clusters, but which have uniform CV structure in the modern language. Smith (2003) for instance argues words recorded like <fri> 'free' would already have been pronounced /firi/ in early Saramaccan, with an epenthetic vowel of very short duration that the dictionary compiler did not register, being aware that no such intrusive vowel was present in the pronunciation or spelling of its English counterpart. Several points of evidence, however, indicate that the compilers were sensitive to the presence or absence of epenthetic vowels. Early Saramaccan wordlists provide alternate forms both with and without epenthesis for many lexical entries, such as sikkisi alongside siksi for E. 'six' and both bulû and nblu for E. 'brow.' This may be due to free variation in pronunciation or competing dialectal forms, or it may indicate that a change in syllable structure was underway at the time
} 
evidence are forms such as bribi from English 'believe' and brusséh from Portuguese aborrecer, which record CR clusters even where the original donor word itself had a supposedly more favorable CVR sequence. Finally, if we presumed that all CRV sequences in loanwords with were initially incorporated into the creole lexicon as disyllabic ${ }^{*} \mathrm{CVRV}$ sequences, we should expect to encounter some lingering trace of that stage, especially if epenthetic vowels in modern creole words are understood to be straightforward continuations of this wordshape. But such intermediary forms are never to be found in early documentation. ${ }^{9}$ Instead we find simply clusters; for instance, the modern Saramaccan word kiíki from English 'creek' is recorded as kriki in Schumann's wordlist, with no trace of an intermediary form of the shape kiriki. The same holds true for all comparable cases.

What is clear is that epenthetic vowels were introduced in the environment $C_{-} R$ at some stage in the history of Saramaccan and Ndyuka. Aceto does not object to the postulation that epenthesis in CR clusters, usually followed by liquid deletion, is a common and robustly attested process in the maroon creoles. His contribution to the debate is simply that epenthesis did not occur as a part of the initial shared creolization process, but rather that it post-dates Schumann's wordlist in Saramaccan. Even if Smith is correct that epenthetic vocalic reflexes were present in sequences that Schumann recorded as clusters, this may be better understood as a phonetic presence of excrescent vowels as a precursor to epenthesis rather than a true phonological presence at this stage.

Aceto is unconcerned with the issue of prosody in relation to syllable structure, however, and does not commit to particular stress or

\footnotetext{
of recording. Spellings such as bribi and brusséh (mentioned in the text) also challenge the common argument that Schumann and others recorded creole words with clusters simply in order to more closely adhere to the spelling of the original European donor words.

${ }^{9}$ Despite close examination of the $18^{\text {th }}$ century sources, direct evidence is extremely rare and uncertain for the theoretical intermediary stage CVRV- in Ndyuka and Saramaccan, following vowel epenthesis but prior to liquid deletion in input words with CR- onsets. Schumann's 1778 wordlist has only Port. estrella 'star' > tereja (modern teéja), Port. criar 'care for' > kiljà (modern kiijá), E. bully tree > bullitiri , and E. brow > bulû, nblu. Only the first two of these words have survived into the modern language, and kiljà might be better understood as metathesis rather than epenthesis of the sort we would hope to observe. Though there is no alternate form for bullitiri, the word kattantri is attested without epenthesis in the same environment. And these examples are alone; the regularity with which onset clusters are recorded in early Saramaccan presents a difficulty for any theory that insists on the full phonological presence of epenthetic vowels, throughout this language's history, to break up CRonsets in borrowed words.
} 
tone assignments in early stages of Saramaccan. In fact, the implications of this historical analysis of syllable structure have not yet been explored with regard to the development and loss of tone. Aceto himself remarks that tone has little to no relevance to his study. It is to this understudied topic, then, that I turn next in the following section.

\title{
4 Tone loss and preservation
}

There is no empirical reason to doubt that tone and stress were both active features in early Surinamese Creole, the common ancestor of the three modern languages. Stress is present in all three creoles, such that its presence in early Surinamese Creole is very likely. And as to tone, Hubert Devonish (1989: 27, emphasis my one) reasons,

\begin{abstract}
By way of historical reconstruction, it would be logical to conclude that if Saramaccan, representing an earlier stage in the development of Plantation Creole is tonal, and if Djuka, one of the later developments of the $18^{\text {th }}$ century Plantation Creole too is tonal, then Plantation Creole was probably also tonal. One would, therefore, have to regard the development of a stress accent system in Sranan as an innovation.
\end{abstract}

Taking this assumption as a starting point, the next natural question to ask concerns what factors could since have led to the loss of phonological tone in modern Sranan.

\subsection{Previous theories}

Alleyne (1980) and Devonish (1989) have both offered accounts for the loss of phonological tone in Sranan, though they suggest different pathways of cause and effect. Believing that the proto-creole had canonical CV syllable structure, both invoke Dutch influence and a relatively late innovation of complex onsets in Sranan via vowel syncope to explain how stress accent has become more prominent and taken over a role once shared with tone. Under both analyses, Ndyuka and Saramaccan undergo only a trivial change of liquid deletion, and are otherwise conservative.

Alleyne (1980: 44f.) suggests that stress accent in Sranan took over a role that was formerly shared with high tone through analogy to the strong expiratory stress in Dutch, which has indeed unquestionably exercised strong influence on Sranan throughout its development. Since he believes that epenthesis in loanword CR clusters was a product of the initial creolization process, his view requires a secondary process of syncope to re-form consonant clusters in modern Sranan, as a result of the overarching change in the language toward a purely accentual prosodic system. That is to say, Alleyne claims unstressed syllables 
were susceptible to deletion once stress had taken a primary role in the language, as demonstrated in example (1) below.

(1a) 'creek' > ki'ríki > ki'riki > 'kriki (Sranan)

(1b) 'creek' > ki'ríki > 'kiíki (Ndyuka \& Saramaccan)

Devonish (1989: 24f.) takes a related but ultimately opposite approach. He argues that prolonged contact with Dutch impacted the Sranan syllable inventory directly, pressuring Sranan to develop more complex and varied syllable types. He claims that vowels in unstressed syllables, many of which were historically epenthetic, were targeted for deletion in order to produce consonant clusters of the same varieties that were commonly allowed in Dutch. In contrast to Alleyne, Devonish argues that it was as a result of this re-syllabification process that stress accent went from being a secondary feature to a primary feature. In other words, stress became more prominent than tone due to its new role as the main criterion for determining which syllables were available for deletion.

(2a) 'creek' > ki'ríki > 'kríki > 'kriki (Sranan)

(2b) 'creek' > ki'ríki > 'kiíki (Ndyuka \& Saramaccan)

\subsection{A new analysis}

Preconceptions with regard to syllable structure in the Surinamese creoles underlie both diachronic analyses of Sranan tone loss. First, both Alleyne and Devonish assume that the CV syllable structure of Ndyuka and Saramaccan is 'more conservative' than Sranan, representing the earliest shared stage of the creole family. Second, operating under the related assumption that Sranan consonant clusters emerged along with loss of tone, they consider both phenomena to be innovations that occurred in a direct causal relationship to each other.

But Aceto's alternative timeline of syllable restructuring invites a new analysis of tone loss. If Sranan consonant clusters reflect an earlier stage of creole syllabification, as seems likely, this starting point requires markedly different pathways of derivation. Sranan forms can now be relatively straightforwardly derived from early Surinamese Creole, while it is the maroon creole forms that go through a more complex series of sound changes, namely epenthesis and liquid deletion, before arriving at their modern forms.

(3a) 'creek' > 'kríki > 'kriki (Sranan)

(3b) 'creek' > 'kríki > ki'ríki > 'kiíki (Ndyuka \& Saramaccan) 
If the syllable structure of Sranan forms remains relatively constant throughout their development, and no concomitant process of syncope is involved in the loss of tone, other factors must be responsible for motivating such a change in the prosodic system. I agree with Devonish and Alleyne that contact with Dutch was involved, but I also think that it is more interesting question to ask what was different about the maroon creoles that contributed to their preservation of lexical tone.

Recall from section 1.3 that heavy syllables represent an innovation in the history of these languages, as they are nearly all the result of liquid deletion. Prior to the creation of heavy syllables via liquid deletion, the assignment of underlying high tone and stress would have coincided naturally. The innovation of heavy syllables created new potential for mismatch between the location of high tone and main stress, as heavy syllables could draw stress away from the mora bearing underlying high tone.

Though the case of Ndyuka 'feemúsu 'bat' presents a particularly clear example of stress/tone mismatch resulting from epenthesis and liquid deletion, we need not even look that hard to find such a case. Even in monosyllabic words with heavy vowels, there is a mismatch between tone and stress inasmuch as stress is a syllabic phenomenon, potentially playing out over two adjacent morae of a heavy syllable, whereas tones are borne by individual vowels. For instance, all the vowels in both Saramaccan fiì 'feel' and fií 'free' are within stressed syllables, but it cannot also be said that they all bear high tone. No comparable mismatch arose in Sranan (which, since it retained original onset clusters, never produced heavy syllables that could potentially attract stress from its original position). Nor indeed was such a mismatch possible in the maroon creoles prior to their late innovation of heavy syllables.

It is not a new idea that the innovation of heavy syllables through epenthesis and liquid deletion prompted shifts in stress placement in Ndyuka (Huttar 1972) and Saramaccan (Rountree 1972). My analysis simply applyies this old observation to the comparative issue of tone in the Surinamese Creole family. Changes to syllable structure in Ndyuka and Saramaccan crucially affected the status of stress and tone by distinguishing their location, such that they no longer overlapped unconditionally. This established independent behavior for both prosodic phenomena, and reinforced their continuing presence in the maroon creoles.

Meanwhile Sranan maintained the older, identical distribution of stress and high tone. With fully redundant tone and stress assignments, Sranan was susceptible to prioritization of one over the other. Only at this point did contact phenomena come into play. With Dutch heavily 
influencing Sranan development nearly from the very beginning, the Sranan prosodic system was leveled in favor of stress accent rather than tone, but crucially, only since pre-existing redundancy within the prosodic system made it vulnerable to leveling of this kind.

Thus, it may be better to understand the presence of complex clusters in Sranan neither as a natural side effect of tone loss (as per Alleyne), nor even as an actively contributing factor to it (as per Devonish), but rather as the key feature that makes Sranan different from its close creole relatives. It was not an innovation that induced tone loss. Instead, it was the opposite innovation in Ndyuka and Saramaccan-the removal of liquid clusters, and consequent development of bimoraic syllables-that gave tone a more active phonological role to play and new justification for perpetuating distinctive phonological tone in an otherwise unnecessarily complex prosodic system.

\section{Conclusion}

Re-syllabification producing heavy syllables in the maroon creoles has led to stress/H-tone mismatch, establishing and reinforcing independent functional roles for both prosodic phenomena in contrast to their redundancy in Sranan. Though Ndyuka and Saramaccan maintain both tone and stress like an earlier stage of the language, it is misleading to refer to these creoles as 'more conservative' than Sranan, as they are actually more innovative in other respects.

Applying this as a broad label has led previous accounts of Surinamese Creole prosody to ignore the possibility that it was not a unique contact-induced innovation on the part of Sranan that led to tone loss. The dual process of vowel epenthesis and liquid deletion in the maroon creoles might be better viewed as the relevant innovation to the discussion of diachronic changes in the prosodic systems of Surinamese creole languages.

\section{Comments invited}

PiHPh relies on post-publication review of the papers that it publishes. If you have any comments on this piece, please add them to its comments site. You are encouraged to consult this site after reading the paper, as there may be comments from other readers there, and replies from the author. This paper's site is here:

http://dx.doi.org/10.2218/pihph.1.2016.1694 


\section{Author contact details}

Emily Barth

203 Morrill Hall,

Ithaca,

New York 14853

elb252@cornell.edu

\section{References}

Aceto, Michael. 1996. Early Saramaccan syllable structure: an analysis of complex onsets from Schumann's 1778 manuscript. Journal of Pidgin and Creole Languages 11(1). 23-44.

Alleyne, Mervyn C. 1980. Comparative Afro-American: An historicalcomparative study of English-based Afro-American dialects of the new world. Ann Arbor: Karoma.

Devonish, Hubert. 1989. Talking in tones: A study of tone in AfroEuropean Creole languages. Christ Church \& London: Karia Press \& Caribbean Academic Publications.

Devonish, Hubert. 2002. Talking rhythm stressing tone: The role of prominence in Anglo-West African creole. Kingston: Arawak.

Good, Jeff. 2009a. A twice-mixed creole? Tracing the history of a prosodic split in the Saramaccan lexicon. Studies in Language 33(2). 459-498.

Good, Jeff. 2009b. Loanwords in Saramaccan, an English-based creole of Suriname. In Martin Haspelmath \& Uri Tadmor (eds.), Loanwords in the world's languages: A comparative handbook, 918-943. Berlin: De Gruyter Mouton.

Huttar, George L. 1972. A comparative word list for Djuka. In Joseph E. Grimes (ed.), Languages of the Guianas, vol. 1, 12-21. Norman OK: Summer Institute of Linguistics of the University of Oklahoma.

Huttar, George L. \& Mary Huttar. 1972. Notes on Djuka phonology. In Joseph E. Grimes (ed.), Languages of the Guianas, vol. 1, 1-11. Norman OK: Summer Institute of Linguistics of the University of Oklahoma.

Huttar, George L. \& Mary Huttar. 1994. Ndyuka. London: Routledge. McWhorter, John \& Jeff Good. 2012. A grammar of Saramaccan creole. Berlin: De Gruyter Mouton.

Rountree, Catherine. 1972. Saramaccan tone in relation to intonation and grammar. Lingua 29. 308-325.

Rountree, Catherine, Jajo Asodanoe \& Naomi Glock. 2000. Saramaccan word list (with idioms). Paramaribo: SIL. 
Schuchardt, Hugo. 1914. Die Sprache der Saramakkaneger in Surinam. Amsterdam: Johannes Müller.

Schumann, Christian L. 1783. Neger-Englisches Wörterbuch. Editio tertia, Paramaribo, MS, Moravian Archives Utrecht, no 648 / Moravian Archives Paramaribo.

Smith, Norval. 2003. New evidence from the past: to epenthesize or not to epenthesize: that is the question. In Ingo Plag (ed.), Phonology and Morphology of creole languages, 91-108. Tubingen: Niemeyer. 